so they did not feel competent to express dissent or assent in the matter. In the third place, this is not the only occasion when injections of fluid have been practised with insufficient data, even with the highest objects in view. Indeed, have not recent events shown that there was for a moment a danger lest a wave of enthusiasm should swamp the intelligence of the College of Physicians, and this danger was only averted by the better judgment of a majority and the sagacity of its guiding spirit? This I conceive to be the explanation of the limited vitality of the pilocarpine craze-a vitality which has been further limited oy Dr. Politzer, who at least, it must be admitted, may fairly claim to set bounds to the employment of an agent which he was the first to apply to ear disease.

The bubble remedy, chameleon-like in its hues, occasionally assumes the aspect of a surgical procedure. In approaching the subject as delicately as possible, let me say I have sometimes hoped it may be possible that there exists in the human mind a faculty-undeveloped unless called into activity-which permits the possessor of it to persuade himself of the inutility and general harmfulness of some portion of the human body (not in the precise instance of his own body, but in that of others). Unless this delusion is within the range of possibility, how are we to explain the determination with which some practitioners exirpate an apparently unoffending portion of the organism for reasons which appear to be not only quite illogical, but which require the profoundest ingenuity even to enunciate? For example, I have been asked to give an opinion somewhat in this way: "I am suffering from [here follow a variety of symptoms which include deafness and tinnitus, but by no means conclude with these troubles]. Do vou think I should be cured ty the removal of my [right or left] middle turbinated bone?" This upon examination being found quite healthy, the opinion in the negative is given without much difficulty, without the expenditure of many words or any comments. The same question has, $I$ know, been asked of many others besides myself. As a surgical procedure, this operation is outside the pale of serious discussion, and I mention it only as an example of a bubble remedy that the very mention of it may possibly hasten its inevitable bursting.

If this operation or mutilation (whichever the reader may elect to term it) is devoid of plausibility, it was not so with another, which is now defunct-viz., division of the tensor tympani muscle, but which, at the period of its birth and early in its brief and chequered career, attracted considerable attention. The conception was not wanting in brilliancy if the results of the proceeding included dulness (in hearing), and it was easy and reasonable at first sight to imagine that the division of this muscle would relieve permanent tension, especially if it had undergone permanent contraction. I have even heard it alluded to at one of the medical societies in London as a recognised operation. It may have been recognised, but certainly by those who were familiar with its results (and especially by those upon whom it was performed) it was recognised as a failure so far as any change for the better in hearing was concerned, and a very decided change for the worse in the cases which came before my notice. I have elsewhere described it as including in its history "a flight of the imagination, a brief notoriety, and a burial in oblivion so rapid as falls to the lot of few achievements in surgery," and I see no reason to alter this description in paying a tribute to the dead.

Such are some of the bubble remedies which float over the area of aural surgery, but which "vanish into thin air" as they emerge into the clear light of day.

Savile-row, $W$.

\section{GOUTY FINGERS.}

By EMIL PFEIFFER, M.D., Wiesbaden.

THE celebrated English physician, William Heberden, in "nis Commentaries, published shortly after his death, about the end of the last century, has a chapter under the heading "De Nodis Digitorum," the tenour of which runs as follows "Nunquam rite intellexi naturam tumorum, qui interdum nascuntur, ad pisi magnitudinem, prope tertium digitorum articulum. Nihil certe illis commune est cum arthridite;

\footnotetext{
I Gulielmi Heberdeni Operæe Medica Commentarii, cap. xxviii., 1802.
}

quoniam in multis reperiuntur, quibus morbus ille est incognitus. Per hominis setatem manent, vacant omni dolore, neque spectant ad ulcerationem. Proinde deformitas major est quam incommodum : quamquam motus digitorum aliquantulum impeditur." From this description these formations have in subsequent publications been named "Heberden's nodes," the name by which they are known at the present day. The accompanying illustration, Fig. 1, taken from a cast in the museum of St. Bartholomew's Hos. pital, London, and copied from Dr. A. E. Garrod's work, ${ }^{2}$ gives a very faithful representation of the affection. Heberden's

\section{FIc. 1.}

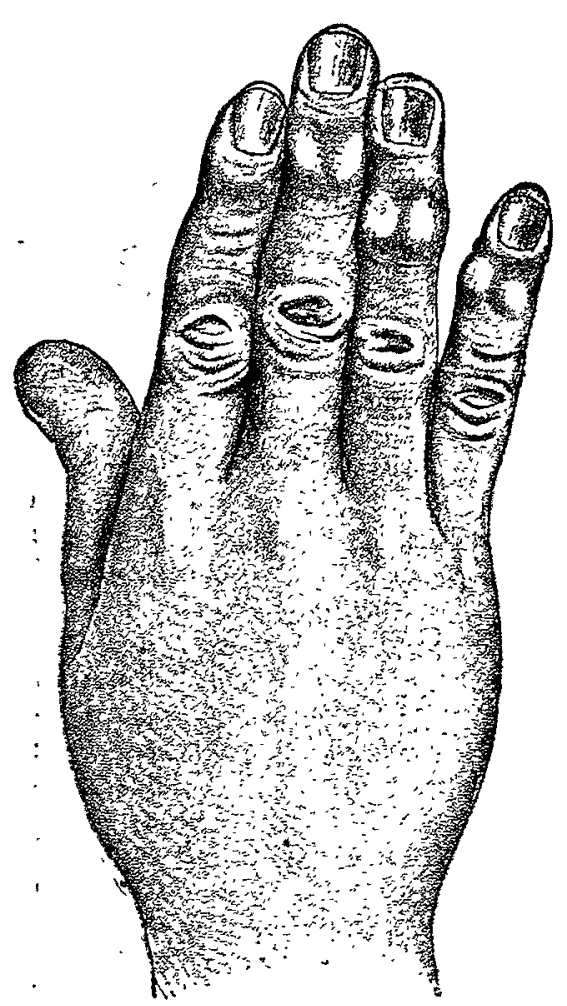

doubts regarding the formation of the nodes described by him were twofold. While he was unable to determine the exact nature of the materials of which they were composed, as well as the parts involved, he could not arrive at a decided opinion as to the cause of the affection.

As to the first point, we have been informed by the anatomical investigations of Charcot that the nodes arise from exostoses round the heads of the second and third phalanges. These exostoses are well shown by the drawings which this author has published (Fig. 2). ${ }^{3}$ It is evident from these

Fig. 2.
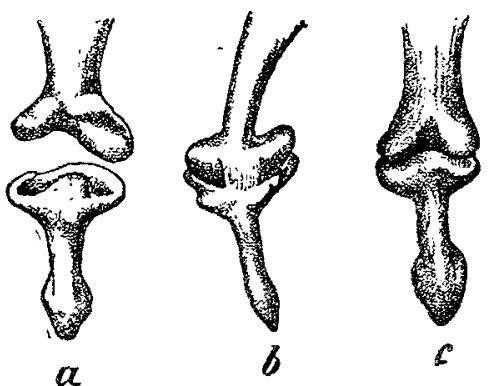

a represents the phalanges from the back, and $b$ the side view. For purposes of comparison he aives a delinea tion of the dorisal surface of $a$ normal phalangeal joint, shown in $c$.

engravings that the nodes are formed by real exostoses and have nothing to do with the tophi of gouty patients.

The second point-the etiology of the disease-has given rise to much greater difference of opinion among writers on this subject. From the little that Heberden wrote we may conclude that he had occupied himself mainly with this question, and that his doubts as to the nature of the nodes were, perhaps, essentially connected with their etiology; but he leaves us in no doubt as to his opinion that they have "no connexion with gout, being found," as he says,

2 A Treatise on Rheumatism and Rheumatoid Arthritis. London: Griffin, 1890. Fig. 15, p 266.

$\because$ (Euvres Completes, tom. vii., planche 1, figs. 4, 5, 6. Paris, 1889 
"in persons who never had it." The most decided opponent to this teaching is Begbie, ${ }^{4}$ who, with reference to the above quoted extract from Heberden's work, writes :-

"Many years have passed since Heberben suggested and answered the question thus proposed, and few, I apprehend, of those who have since perused his writings have felt themselves disposed to differ from him in opinion, and give a different answer. Nevertheless, the question, if I mistake not, admits of a distinct reply; and those little knobs, which physicians in all ages must have noticed and considered, are in reality intimately connected with gout, though they are often found in those who have never experienced a fit of the disease. They are the product of the gouty diathesis; they are the deposits of the gouty blood, and are not less certain indications of the habit than the enlarged cervical glands and irregular cicatrices which mark the deposit and progress of tubercle are of the strumous constitution. Both are guides and landmarks to the inquiring and observing physician; both are eminently suggestive as points of diagnosis and as indications of treatment-not only as regards the individuals themselves in whom these manifestations appear, but as respects the many who may be related to them by ties of kindred blood. $I$ have again and again traced the rise and progress of these little knobs to their full development; I have seen that progress slow and almost imperceptible from year to year, and have seen it equally rapid and observable during the course of as many months. They are occasionally the result of an inflammatory affection of the fingers, more or less acute in its character, and attended by the same constitutional disturbance which marks the fit of gout; but more commonly they are the consequences of a slow and chronic disorder, in which dys. peptic derangement has been chiefly noticed; while occasional twitches of pain in the fingers and $a$ sense of fulness and stiffness there have been the only forerunners of those morbid products which are destined to last through life. They are found chiefly among the upper classes, or among the luxurious and well fed of their dependants, and are seldon or never found disfiguring the hands of the industrious labourer or of the hard-working mechanic. I have never seen these knobs but in connexion with gout or the gouty diathesis, and their presence in the fingers of a patient or of a blood relative has often led me to a right diagnosis of some obscure affection, or been the means of throwing light on the nature of some anomalous symptoms which had baffled all attempts to unravel."

Charcot, ${ }^{5}$ on the contrary, is of the same opinion as Heberden, and denies all connexion with gout. From his anatomical investigations he is led to consider the disease to be a special form of rheumatoid arthritis. In numerous cases observed at the Salpêtrière he was able to convince himself that the disease occurs in many persons who had never had an attack of gout, and that the anatomical changes were those of rheumatoid arthritis or rheumatic gouti.e., degeneration of the cartilages and exostoses, $\mathrm{He}$ is, however, compelled to sum up his conclusion with the words: "Enfin ces petites nodosités peuvent coincider avec la goutte, ainsi que j'ai eu moi-même l'occasion de le constater récemment. Dans le cas dont il s'agit les nodosités avaient précédé la goutte de plusieurs années."

Recent English authors (Drs. Alfred B. Garrod, Duckworth, and Archibald E. Garrod) are much less confident as to the cause of the nodes. Dr. Alfred B. Garrod ${ }^{6}$ believes Heberden's assertion that "they have no necessary connexion with genuine gout to be correct"; and continues, "As far as my own experience goes, I have very seldom seen them in patients who were sufferers from true gout." Dr. Archibald E. Garrod" is of the same opinion; only he adds that he has himself seen such nodes in cases in which there were clear histories of gout, but of no other articular affection." Duckworth ${ }^{8}$ goes much

4 Contributions to Practical Medicine. Edinburgh: Black, 1862, p. 28. 5 CEurres Completes, tom. vii, Paris, 1889, p. 217. London, 1876, p. 503.

7 A Treatise on Rheumatism and Rheumatoid Arthritis. London, 890, p. 266 .

8 A Treatise on Gout. London, 1889, p. 71 further than this. He not only contends that in a good many cases the nodes of Heberden are undoubtedly of gouty nature, but even proves by anatomical facts that the changes. in the cartilages and the exostoses found by Charcot are very frequently of an undoubtedly gouty nature. The changes in cases of true gout characterised by deposits of urates may go on to complete bony ankylosis - a result which also occasionally takes place in Heberden's nodes. Duckworth quotes a very striking case (of Dr. Gee), in which the third joints of several fingers were stiffened by bony ankylosis, while all the other joints showed exostoses. In this case not only true fits of gout had taken place, but the post-mortem examination revealed "unequivocally gouty changes with small scattered uratic deposits." The case is minutely described and illustrated by drawings. The same point of view is taken by Lecorché," who says: "Nous croyons que, chez les femmes, en particulier, les nodosités d'Heberden peuvent fort bien être l'indice de la diatbèse goutteuse, se traduisant d'ailleurs par diverses manifestations viscérales : asthme, dyspepsie, sciatique, etc., et surtout par les modifications caractéristiques de l'urine et du sang." As instances in point, he quotes the cases of two female patients who belonged to gouty families, and in whom, in addition to the presence of the nodes of Heberden, there were many symptoms of anomalous gout.

For some years past I have observed with special interest. the nodes of Heberden on the numerous patients suffering from gout or rheumatic gout whon I see here at Wiesbaden. Fig. 3.-UPPER Part.

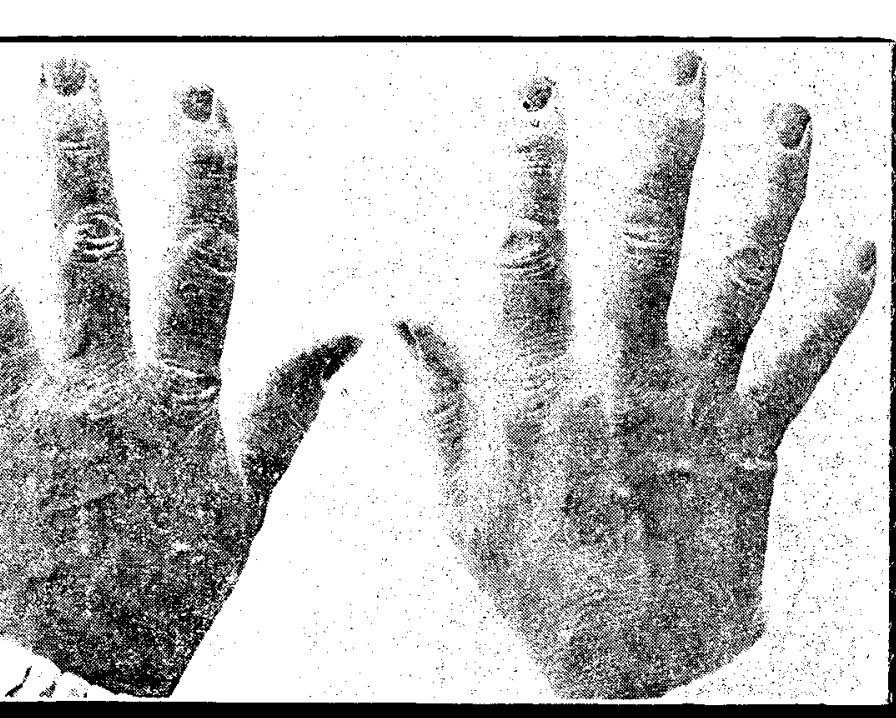

Mrs. Doris N- of Bremerhafen, sixty years of age.

To my mind the nodes of Heberden, as they are represented in Fig. 1, in the form of small tumours of the size of a pea, are only a part of the changes involving the whole joint. When we consider and examine the tirst stages of the disease, as shown in Fig. 3, we find that the whole region of the third joint is enlarged, not only on the back, but also on the side and towards the volar surface. On the back of the fingers the usual furrows which mark the regions of normal joints when the fingers are stretched have disappeared, or are even supplanted by an elevation, the whole region of the joint forming a kind of bunch or knob. This very singular appearance of the joint becomes still more marked when all the third joints of the hand are similarly disfigured. Even on the volar surface of the fingers the joints can be felt as thickened knobs or pads. In these cases at the commencement the heads of the two phalanges which form the third joint are enlarged on all sides, the nodes of Heberden making their appearance at a much later period of the disease, in the form of large exostoses on the heads of the second phalanges. When we trace the rise and progress of the affection to its full development, we come to the following clinical description: Sometimes peculiar sensations in the fingers precede for a long time the outbreak of the disease. A lady was troubled with a feeling of numbness in the fingers for several years, but no sign of change in the joints could be detected. When I saw her again two years afterwards the numbness still con. tinued, while several of the third joints in both hands

9 Traite de la Goutte. Paris, 1884, p. 122. 
showed the changes above described. In most cases pain is present in the beginning of the disease. The statement of Heberden - "Vacant omni dolore"-is certainly incorrect for the first stages of the disease, while all authorities are unanimsus in saying that most cases present either spontaneous pain or pain when the joints are pressed or moved.

In cases in which the morbid processes are dying or have entirely died out, as not unfrequently happens with people at an advanced age, the swelling of the joints and the nodes of Heberden remain ; but pain in the parts, whether spontaneous or on pressure, becomes entirely absent. The pains are, as mentioned above, generally greatest in the beginning of the disease. The patient from whom Fig. 3 is taken suffered from severe pains for several years. A course of baths which she underwent at Eilsen in Germany gave no relief, and it was not until after a series of baths taken at Wiesbaden that all pain disappeared. The patient from whom Fig. 4 is taken has still very much pain on pressure, although the disease is much more advanced. As time goes on the last joints of the fingers usually become more and more thickened, and ultimately the nodes of Fieberden make their appearance, accompanied with various symptoms of a vague or anomalous character. In Fig. the affection is shown in a more advanced stage, and in several of the joints, especially in the little finger of one and, the beginning of the nodes is distinctly observable.

FIG. 4.

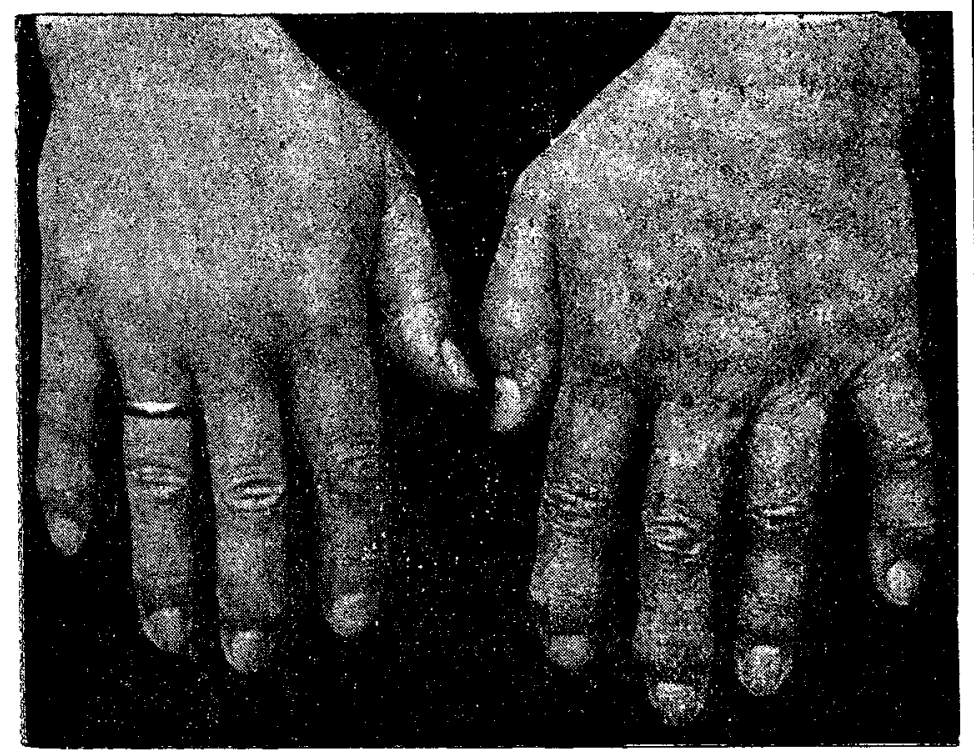

Mrs. H- of Hamburg, fifty-tive years of age.

As the thickening of the heads of the phalanges continues to increase the movements of the joints become more and more impeded, until in the later stages of the disease complete ankylosis becomes established. In some cases the affection shows itself in one or two fingers only, while in other cases all the third joints become involved, the little finger being not unfrequently the first to be affected. In the very rare cases in which the second joints of the fingers become implicated similar changes are observed in the joint of the thumb. I have met with only one instance of this ; Buck worth's case above mentioned being another. In other cases the joint of the thumb remains unaffected. I have never observed this affection in the toes.

The persons most liable to be attacked are elderly people above fifty, but I have seen the disease completely developed in a female patient of forty, in whom it had begun at thirtysix years of age. My opinion is in complete accordance with that expressed by Begbie. I consider the affection to be a symptom of true gout, for I have not only seen the disease in a considerable number of cases which had been preceded by attacks of gout, or in which uratic deposits were actually present, but I maintain, in opposition to the opinion of Garrod and Charcot, that this is frequently the case. On the other hand, I must also admit that the disease is found in many persons who have never been subject to gont. From Heberden's point of view the apparent absence of gout in so many of these cases would be a sufficient argument to preclude entirely the gouty nature of the affection; but at the present day we cannot look upon certain morbid processes as having no connexion with gout on such narrow grounds, as we know that many vague and various affections of a gouty nature not unfrequently occur in persons who have never had an attack of gout. The symptoms of anomalous gout are well known to most physicians, especially in England, and in many cases a diagnosis can be established in the absence of decided outbreaks of the disease or of uratic concretions. An acute attack of gout can only be considered as one of the most frequent symptoms of the gouty condition, and not as its invariable and only certain sign. There is a large number of cases in which the most extensive uratic deposits are developed in the absence of acute symptoms or of preceding outbreaks. In the cases in which nodes are developed without acute symptoms of gout or without uratic deposits, a considerable number are found to belong to families in which the gouty condition is hereditary. Begbie and Lecorché quote such cases, and Duckworth relates the case of a physician in whose family the affection was traceable through three generations. In one branch of the family it was found to be clearly connected with gout. A brother of the patient, in whom the disease had shown itself very distinctly, had an acute attack of gout some time ago. But even the pronounced tendency of the disease to be hereditary is in itself a strong argument in favour of its being a symptom of gout. Rheumatic affections are no doubt also hereditary, but never nearly to the same extent. In the former several successive generations of a family will show precisely the same changes, and only these; while in hereditary rheumatism in the parts attacked a marked difference in this respect is seen to obtain. In one generation the disease attacks the hands, in another the large joints, and so on.

I am inclined myself to consider the above-mentioned changes in the third joints of the fingers to be as typical a symptom of true gout as the appearance of an attack show. ing itself in the ball of the great toe. The fact of its being mainly a disease of advanced life and of the female sex is quite compatible with its gouty nature, for it is to these chronic forms of gout that females and elderly people are more particularly subject. In the male sex and in those in whom the influence of heredity is very strong, outbreaks of gout usually occur at an earlier period than in those who, living more temperate lives, become subject to the chronic forms of the disease at a later period of life In this con. nexion I would mention a case described later on, in which both mother and darghter showed the disease. The changes in the fingers appeared much earlier in the daughter than in the mother, a feature which is quite characteristic of hereditary gout. The most conclusive reason which leads me to consider the disease as being of an entirely gouty nature is furnished by chemical examination of the urine. Indeed, in many of these cases the only symptoms of gouts which can be detected are those changes which are seen to take place in the urine, and which, as described by me in THE LANCET of 3rd January last, are pathognomonic of that disease, and alone sufficient to establish its diagnosis. I will relate a few cases in illustration of this; with the exception of the fifth they are those in which no acute attacks or other symptoms of gout had occurred.

Mr. P__ of Athens, sixty.one years old, shows Heberden's nodes in one of the third phalangeal joints. The twenty-four hours' urine collected at the first bath was found to be very acid ; it contained $0.5988 \mathrm{gr}$. of uric acid; $100 \mathrm{~cm}$. of it, passed through a filter with $0.5 \mathrm{gr}$. uric acid, yielded, with strong hydrochloric acid, only the sixth part, and passed through a filter with 0.2 gr. uric acid only half of the uric acid originally contained in the urine. After the twentieth bath the quantity of the uric acid in the twenty-four hours' urine was seen to be only $0.3544 \mathrm{gr}$.

Mrs. $\mathbf{N}$ - of Berlin, fifty-three years old, has the described changes in the third joints of all the fingers, which are painful on pressure. The twenty-four hours' urine collected before the first bath was very acid, containing as much as $0.6515 \mathrm{gr}$. of uric acid; $100 \mathrm{ccm}$. of it, after filtration through $0.5 \mathrm{gr}$. of uric acid, yielded only the fourth part, and after filtration through $0.2 \mathrm{gr}$. of uric acid only the third part of the uric acid originally contained in the urine. After twenty baths the uric acid secreted in twenty-four hours was only $0.3657 \mathrm{gr}$.

Mr. B - seventy years old, shows the described changes of the third joints in several fingers. The urine of twentyfour hours collected at the first bath was very acid, containing $0.4440 \mathrm{gr}$. of uric acid; $100 \mathrm{ccm}$. of it, after filtration through $0.2 \mathrm{gr}$. of uric acid, yielded only half of the original quantity of uric acid with strong hydrochloric acid. After the twentieth bath the quantity of uric acid secreted in twenty-four hours was only $0.0154 \mathrm{gr}$.

Mrs, de S - , from America, fifty-nine years old, has all 
the third joints of both hands implicated. The disease began at fifty years of age. The quantity of uric acid secreted in twenty-four hours was $0 \cdot 4045 \mathrm{gr}$; $100 \mathrm{ccm}$. of the urine passed through a filter with $0.2 \mathrm{gr}$. of uric acid yielded no trace of uric acid with strong hydrochloric acid. After twenty baths the quantity of uric acid secreted in twenty-four hours was only $0 \cdot 1699 \mathrm{gr}$.

Mrs. $R-$, daughter of the above, thirty-nine years old, has the same changes on the fingers of both hands, the affection having begun five or six years ago. Some years after the beginning of the disease she had the first acute attack of gout in the great toe, which has ever since been a regular occurrence every year. The twenty-four hours' urine collected before the first bath gave $0.4305 \mathrm{gr}$. of uric acid ; $100 \mathrm{ccm}$., after filtration through $0.2 \mathrm{gr}$. of uric acid, yielded no trace of uric acid with strong bydrochloric acid. After twenty baths the quantity of uric acid secreted in twenty-four hours was only $0.0318 \mathrm{gr}$.

Mrs. M-, from Aix-la-Chapelle, seventy years old, shows the described changes in the third joints of several fingers of both hands. The twenty-four hours' urine was very acid, containing $0 \cdot 1646 \mathrm{gr}$. of uric acid; $100 \mathrm{ccm}$ of it, after filtration through 0.5 gr. of uric acid, yielded only some crystals of uric acid with strong hydrochloric acid. After a course of twenty baths the quantity of uric acid secreted in twenty.four hours was $00772 \mathrm{gr}$.

Professor L_- M.D. of Berlin, seventy years old, showed the disease in the third joints of several fingers. The urine of twenty-four hours was very acid, and contained $02301 \mathrm{gr}$. of uric acid ; $100 \mathrm{ccm}$. of it, passed through a filter with $0.2 \mathrm{gr}$. of uric acid, yielded only 39.3 per cent. of the quantity of uric acid originally present. As the patient came to Wiesbaden only for a short time, the influence of the baths cannot be given.

In these cases it is evident that all of them presented the conditions of urine characteristic of gout, several of them showing, indeed, these urinary changes in a most marked manner; and further, that during a course of batbs at Wiesbaden they showed the diminution of the quantity of uric acid secreted in twenty-four hours which 1 have described in the above-mentioned paper as heing one of the most certain tests for latent gout. From all these facts we may conclude that the disease in question is of true gouty nature and is based only on gout.

As the nodes of Heberden are only a part of the process, and as the first stages of the disease, which consist in a

Fig. 5.-UPPER Part.

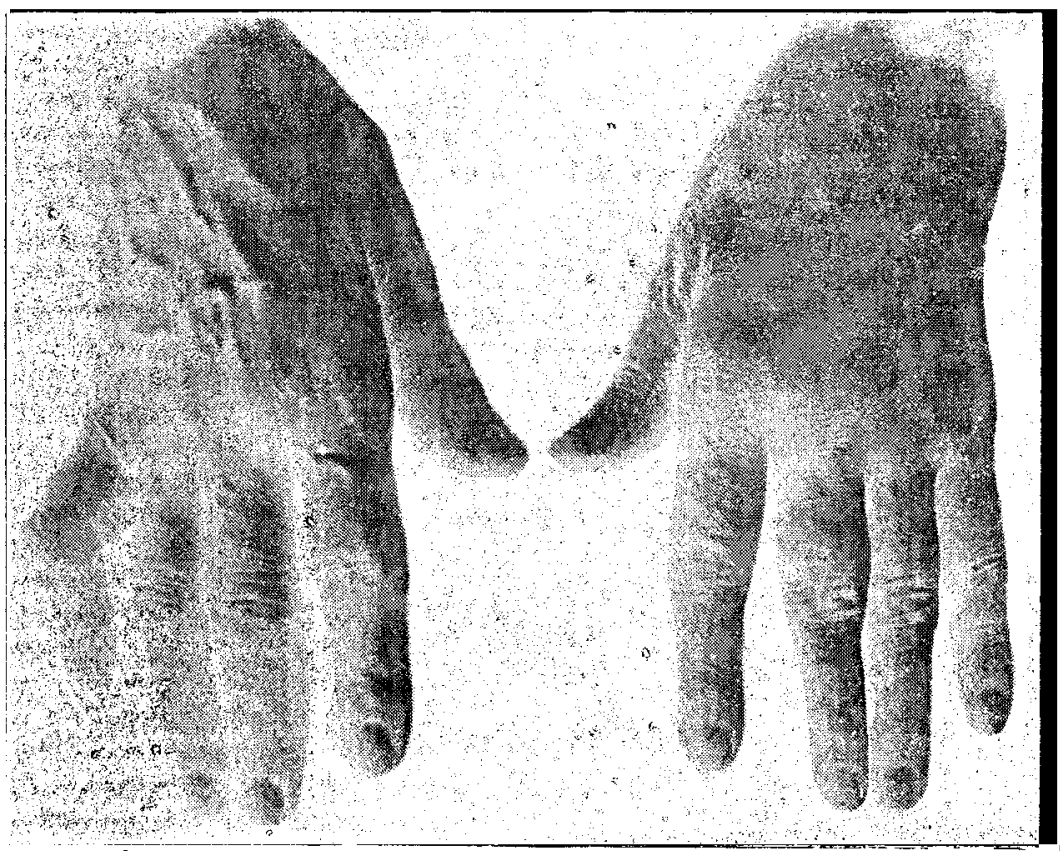

Mrs. K-, from 'Dresden, fifty-four years of age.

general enlargement of the heads of the phalanges, are likewise characteristic, the term "gouty fingers" would seem more applicable than "Heberden's nodes," which term should be confined to the nodes at a more fully developed stage of the disease ; and a further conclusion may be drawn, that the gouty fingers are of a purely gouty nature, and that in their peculiar clinical appearance, which is in the first stages always connected with changes in, or confined to, the third joints of the fingers, they are as characteristic a sym. ptom of gout as an acute attack in the ball of the great toe. It is to be noticed that in cases of rheumatoid arthritis in the hands the third joints of the fingers always remain free from changes. But there are cases of gout in which some joints of the hands are involved while the third joints remain free; so, although it can be said that the disease described as "gouty fingers" is a certain proof of gout, we cannot say when there is an absence of morbid changes in the third joints that the gouty condition is not present. Figs. 5 and 6 will serve to illustrate the difference between the cases depicted in Figs. 3 and 4 and those of rheumatoid Fig. 6.-UPPER PART.

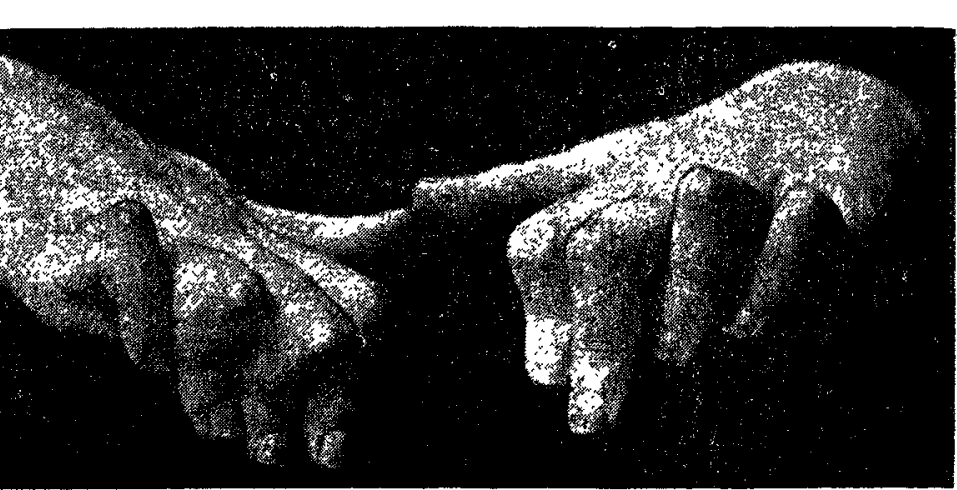

Miss S—, from Wiesbaden, thirty-two years of age.

arthritis. They are taken from two well-marked cases of rbeumatoid arthritis. The nature of the disease is not only proved by the clinical examination, but also by the chemical examination of the urine during a course of baths at Wiesbaden.

Mrs. K - of Dresden, before undergoing a course of baths at Wiesbaden, secreted in the twenty-four hours" urine 0.2805 gr. of uric acid ; after twenty baths the quantity of uric acid secreted in twenty-four hours was $0.2754 \mathrm{gr}$. Miss $\mathrm{S}$ - of Wiesbaden, previous to a course of baths there in the summer of 1888 , secreted $0.1552 \mathrm{gr}$. of uric acid in twenty-four hours, and 0.2216 gr. after twenty days; and in a second course of baths in the summer of $18900.2129 \mathrm{gr}$. at the first bath, and $0.2152 \mathrm{gr}$. after twenty days.

In both these cases we see no diminution of the quantity of uric acid producedby a course of baths; whilein both the urine contained no "free uric acid" at the beginning of the course" of baths, for $100 \mathrm{ccm}$. of the urine yielded with strong hydrochloric acid just the same quantily of uric acid after filtration through uric acid as without filtration. In these cases we see the joints which are always implicated in "gouty fingers" remain entirely free, while all the other joints of the fingers and of the wrist are involved. The third joints are in the same condition as in healthy persons; they are. not enlarged, and remain completely movable, all the other joints of the fingers being either swollen or stiffened. This difference in the hand of rheumatoid arthritis and that of "gouty fingers" is a very striking one.

With respect to the treatment of the disease, I would make the following remarks. In the cases in which there is no pain the only inconvenience suffered is the disfigurement of the hands, especially in the case of ladies; but as most of the subjects of "gouty fingers" are at an advanced. age, this disfigurement is not much felt. The treatment in advanced cases is quite hopeless, as the changes in the bones are beyond remedy.

In cases in which the morbid process is only commencing we must interfere on account of the pain, the imminent disfigurement, and hindrance in movement, or complete stiffness. The best remedies in such' cases are repeated courses of baths, a strict diet, and the continued use of an alkaline mineral water, especially Fachingen. As I mentioned above, in the case of Fig. 3, a single course of baths at Wiesbaden was the means of freeing the patient from all pain.

The diet is described in extenso in the above-quoted treatises on gout, in the work of Ebstein, ${ }^{10}$ and in my work, ${ }^{11}$ to which a diet table for gouty patients is appended.

10 Das Regimen bei der Gicht. Wiesbaden : Bergmann, 1885. 11 Die Gicht und ihre erfolgreiche Behandlung, Wiesbaden : Berg.
mann, 18:1. 